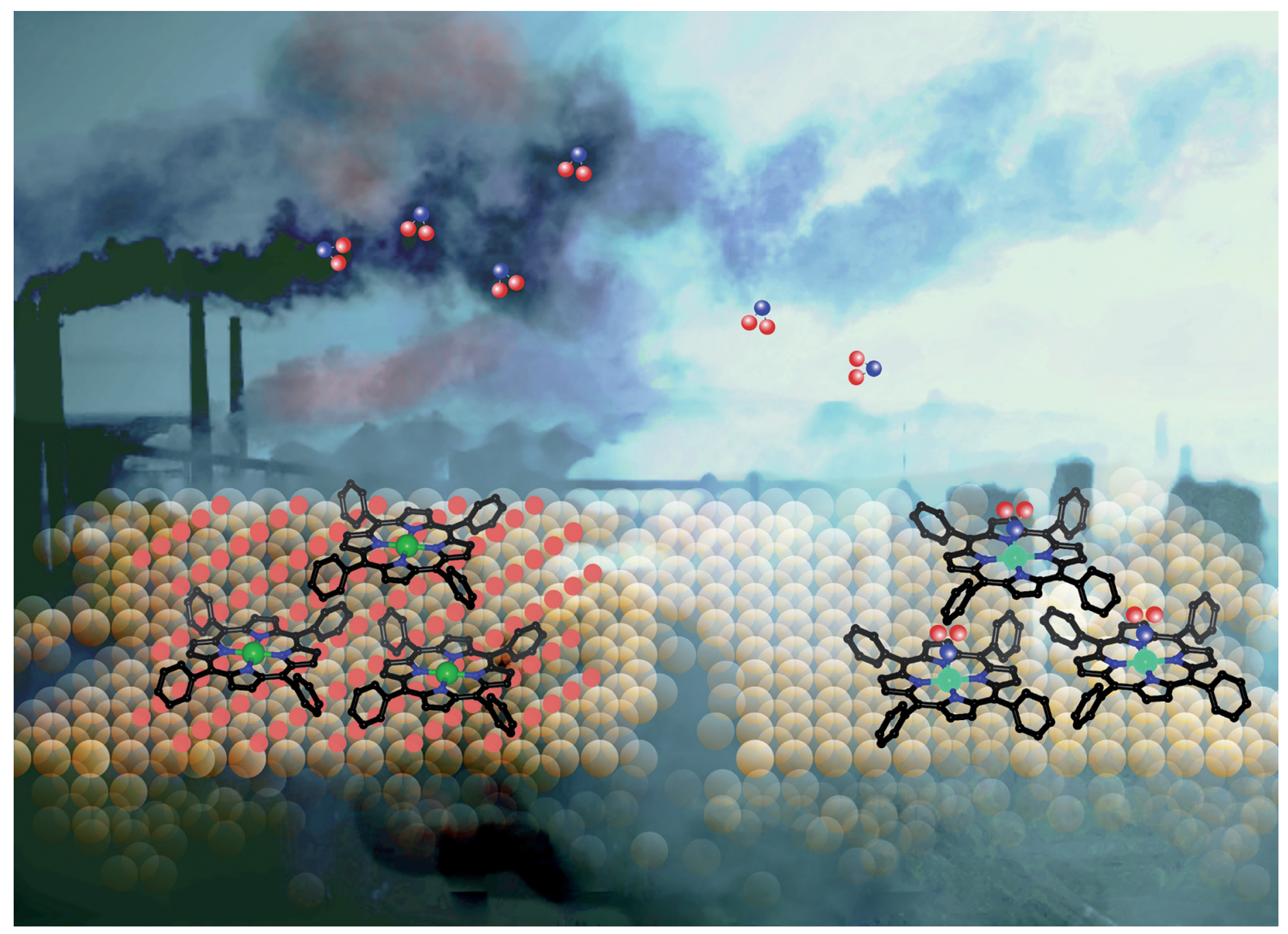

Showcasing collaborative research from University of Padua, Italian Institute of Materials and Peter Grünberg Institute (PGI-6) of Forschungszentrum Jülich, Germany.

Reversible redox reactions in metal-supported porphyrin: the role of spin and oxidation state

The reduced metal ion in the porphyrin molecular array facilitates the formation of the new metal-ligand chemical bond already at room temperature, however, molecular reactivity goes beyond the sole presence of unpaired electrons in the valence shell.

\section{As featured in:}

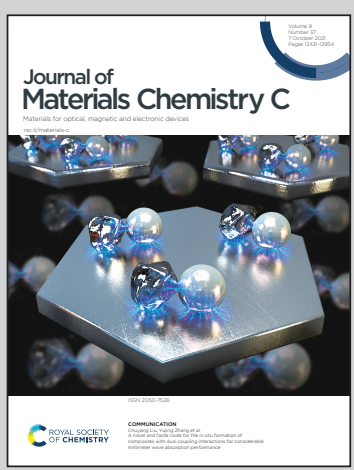

See Iulia Cojocariu,

Silvia Carlotto, Vitaliy Feyer et al., J. Mater. Chem. C, 2021, 9, 12559. 
Check for updates

Cite this: J. Mater. Chem. C, 2021, 9, 12559

Received 13th May 2021 Accepted 26th July 2021

DOI: $10.1039 / \mathrm{d} 1 \mathrm{tc0} 2222 \mathrm{a}$

rsc.li/materials-c

\title{
Reversible redox reactions in metal-supported porphyrin: the role of spin and oxidation state $\dagger$
}

\author{
Iulia Cojocariu, (D) *a Silvia Carlotto, (D) *bc Giovanni Zamborlini, (D) $\ddagger^{a}$ \\ Matteo Jugovac, (D) $\S^{a}$ Luca Schio, (D) ${ }^{d}$ Luca Floreano, (D) d Maurizio Casarin, (D) b \\ Vitaliy Feyer (D) ${ }^{\text {ae }}$ and Claus Michael Schneider ${ }^{\text {ae }}$
}

\begin{abstract}
On-surface molecular functionalization paved the way for the stabilization of chelated ions in different oxidation and spin states, allowing for the fine control of catalytic and magnetic properties of metalorganic networks. Considering two model systems, a reduced Co(I) and an open-shell Co(II) metal-supported 2D molecular array, we investigate the interplay between the low valence oxidation and unpaired spin state in the molecular reactivity. We show that the redox reaction taking place at the cobalt tetraphenylporphyrin/ $\mathrm{Cu}(100)$ interface, stabilizing the low-spin Co(I) state with no unpaired electrons in its valence shell, plays a pivotal role in changing the reactivity. This goes beyond the sole presence of unpaired electrons in the valence state of the Co(॥) metal-organic species, often designated as being responsible for the reactivity towards small molecules like $\mathrm{NO}$ and $\mathrm{NO}_{2}$. The reversible $\mathrm{Co}-\mathrm{NO}_{2}$ interaction, established with the Co(l) leads to the stabilization of the Co(III) oxidation state.
\end{abstract}

\section{Introduction}

Coordination chemistry offers unique possibilities to create new local bonds with metal-organic molecules. By extending this approach to surface chemistry, the tailoring of the electronic and, consequently, the chemical properties of the metalorganic layer is made possible by the interaction with the substrate. ${ }^{1}$ The on-surface stabilized arrays of metal ions in an unusual coordination environment may exhibit enhanced catalytic activity compared to the free molecules. ${ }^{2,3}$ Among others, tetrapyrrolic compounds, such as porphyrins, offer the possibility to chelate at the center of their macrocycle a wide

\footnotetext{
${ }^{a}$ Peter Grünberg Institute (PGI-6), Forschungszentrum Jülich GmbH, 52428 Jülich, Germany. E-mail: i.cojocariu@fz-juelich.de

${ }^{b}$ Dipartimento di Scienze Chimiche, Università degli Studi di Padova,

via F. Marzolo 1, 35131 Padova, Italy

' Institute of Condensed Matter Chemistry and Technologies for Energy (ICMATE),

National Research Council (CNR), c/o Department of Chemistry,

University of Padova, via F. Marzolo 1, 35131 Padova, Italy.

E-mail: silvia.carlotto@unipd.it

${ }^{d}$ CNR-IOM, Lab. TASC, s.s. $14 \mathrm{~km}$ 163,5, 34149 Trieste, Italy

${ }^{e}$ Fakultät $f$ Physik and Center for Nanointegration Duisburg-Essen (CENIDE),

Universität Duisburg-Essen, D-47048 Duisburg, Germany

E-mail:v.feyer@fz-juelich.de

$\dagger$ Electronic supplementary information (ESI) available. See DOI: 10.1039/ d1tc02222a

¥ Present address: Technische Universität Dortmund, Experimentelle Physik VI, 44227 Dortmund, Germany.

$\S$ Present address: Istituto di Struttura della Materia-CNR (ISM-CNR), 34149 Trieste, Italy.
}

plethora of transition metal ions offering an unsaturated site for functionalization. In fact, the addition of axial ligands, such as $\mathrm{O}_{2}, \mathrm{NO}, \mathrm{NO}_{2}$ and $\mathrm{CO}$, can be exploited for inducing further changes in the electronic structure and, in particular, in the spin state of the central metal ion. ${ }^{4-12}$ The unsaturated character of the metal ions in the porphyrins is also the key to the reactivity of a large number of enzymes. Specifically, the coordination of small diatomic molecules with metalloporphyrins are essential for biological processes. ${ }^{13-16}$

In surface chemistry, however, low-temperature conditions are often required for the stabilization of the ligand-metal porphyrin interaction and, currently, the room temperature (RT) coordination is still a challenge. Overcoming this obstacle will allow us to tune the oxidation and spin state of chelated metal ions supported by a metal electrode, thus giving a chance to adjust the desired properties of the organic-based devices in working conditions.

One wonders what promotes the reaction of a metal-organic molecule with gaseous species? On the one hand, it was claimed that unpaired electrons in the valence shell of the chelated metal ion are a key factor in ligand coordination. ${ }^{1,6,17}$ On the other hand, some of the most challenging reactions in organisms are catalyzed by chelated metal ions, where unexpected reactivity corresponds to low valence oxidation states. ${ }^{18-20}$ In this regards, cobalt tetraphenylporphyrin (CoTPP) can be a suitable model system to shine a light on the molecular reactivity, as it can be stabilized either in the reduced $\mathrm{Co}(\mathrm{I})$ or $\mathrm{Co}(\mathrm{II})$ open-shell arrangements. In fact, the choice of the metal substrate strongly influences the CoTPP electronic 
structure upon deposition. While on poorly reactive substrates, such as $\mathrm{Au}(111),{ }^{21}$ the $\mathrm{Co}(\mathrm{II})$ ion in Co-porphyrins $\left(3 \mathrm{~d}^{7}\right.$ configuration) is stabilized in its low spin (LS) state with a single unpaired electron in the valence shell, on more interacting surfaces, e.g. silver and copper substrates, the Co ion is reduced $(\mathrm{Co}(\mathrm{II}) \rightarrow \operatorname{Co}(\mathrm{I}))$ and stabilized in a $\mathrm{LS} 3 \mathrm{~d}^{8}$ configuration. ${ }^{22}$ Indeed, the $\mathrm{Co}(\mathrm{I})$-porphyrin systems supported by silver and copper surfaces show null or very week XMCD signal. ${ }^{22,23}$ The $\mathrm{Co}(\mathrm{I})$ supported by $\mathrm{Ag}(111)$ enables the binding of nitric oxide (NO) at $140 \mathrm{~K}$, weakening the $\mathrm{Co}-\mathrm{Ag}$ interaction because of the surface trans-effect. ${ }^{4,24,25}$

In this communication, we examine more deeply the axial ligand binding of $\mathrm{NO}_{2}$ to a CoTPP network grown on bare and oxygen-modified $\mathrm{Cu}(100)$, disentangling the relation between oxidation and spin state of the metal ion, as well as elucidating the electronic configuration that promotes the reaction with the gaseous species. We demonstrate that, while the presence of the unpaired electrons in the valence shell of $\mathrm{Co}$ (II) is not a crucial factor in this ligand coordination, the presence of the reduced $\mathrm{Co}(\mathrm{I})$ metal ion in the molecular array facilitates the formation of the new $\mathrm{Co}-\mathrm{NO}_{2}$ chemical bond already at RT. In particular, we show that the Co(III) ion is stabilized in a $2 \mathrm{D}$ molecular array of CoTPP on $\mathrm{Cu}(100)$ by the trans-effect localized along the $\mathrm{Cu}-\mathrm{Co}-\mathrm{N}$ axis. The functionalization of the metal-organic array at RT is then pivotal for a fine-tuning of the desirable electromagnetic properties of molecular-based devices in working condition.

\section{Results and discussion}

A detailed comprehension of the changes induced by the surface in the supported CoTPP network may take advantage of a few words about the free molecule. Consistently with the presence of a LS Co(II) $3 \mathrm{~d}^{7}$ central ion $(S=1 / 2)$, the CoTPP static magnetic moment is $\mu^{\mathrm{S}}=1.73 \mu_{\mathrm{B}}$, while its effective magnetic moment is $\mu^{\mathrm{e}}=1.92 \mu_{\mathrm{B}}{ }^{26}$ The square planar coordination of Co(II) in free CoTPP $\left(D_{4 \mathrm{~h}}\right.$ symmetry $\left.{ }^{21}\right)$ lifts the five-fold degeneracy of the Co $3 \mathrm{~d}$ atomic orbitals (AOs) to generate $\mathrm{a}_{1 \mathrm{~g}}$ $\left(\mathrm{d}_{z^{2}}\right), \mathrm{b}_{1 \mathrm{~g}}\left(\mathrm{~d}_{x^{2}-y^{2}}\right), \mathrm{b}_{2 \mathrm{~g}}\left(\mathrm{~d}_{x y}\right)$ and $\mathrm{e}_{\mathrm{g}}\left(\mathrm{d}_{x z, y z}\right) 3 \mathrm{~d}$-based MOs, whose relative energy positions and 3D contour plots (CP) are displayed in the left panel of Fig. S1 (ESI $\dagger$ ). In a multilayer phase and when deposited on an inert substrate $(\mathrm{O}-\mathrm{Cu}(100)$ in the present study), the free molecule properties are preserved. The oxygen dosing is a consolidated protocol to passivate reactive substrates, including metals. ${ }^{27,28}$ At saturation, $\mathrm{Cu}(100)$ displays a characteristic $(\sqrt{ } 2 \times 2 \sqrt{ } 2) \mathrm{R} 45^{\circ}$-O reconstruction, where a significant quenching of the charge transfer at the organicmetal interface is expected. ${ }^{29-31}$ Similarly to the free molecule, CoTPP deposited on $\mathrm{O}-\mathrm{Cu}(100)$, has a LS state with a single unpaired electron occupying the $3 \mathrm{~d}_{z^{2}}$-based MO (Fig. S1, right panel, ESI $\dagger$ ). Such an unpaired electron in the molecular electronic structure has attracted great attention in coordination chemistry studies ${ }^{4-6,17}$ and it is also a key point in the present investigation (details about the stability of the different spin states and MOs compositions in CoTPP are reported in ESI $\dagger$ ). Upon deposition on a metal substrate, the molecular layer in direct contact with the surface can experience chemical changes induced by the charge transfer at the metal/organic interface. At variance with $\mathrm{CoTPP} / \mathrm{O}-\mathrm{Cu}(100)$, where the $\mathrm{Co}$ ion preserves the $3 \mathrm{~d}^{7}$ configuration of the free molecule, $\mathrm{Co}$ (II) is expected to reduce to $\mathrm{Co}(\mathrm{I})$ on more reactive surfaces, such as silver and copper, which implies a $3 \mathrm{~d}^{8}$ configuration with no unpaired electrons in 3d-based MOs. ${ }^{4,32}$ In order to confirm the stabilisation of $\mathrm{Co}(\mathrm{I})$ and $\mathrm{Co}(\mathrm{II})$ oxidation states in the CoTPP monolayer deposited on the reactive $\mathrm{Cu}(100)$ and passivated $\mathrm{O}-\mathrm{Cu}(100)$, respectively, we performed X-ray photoemission

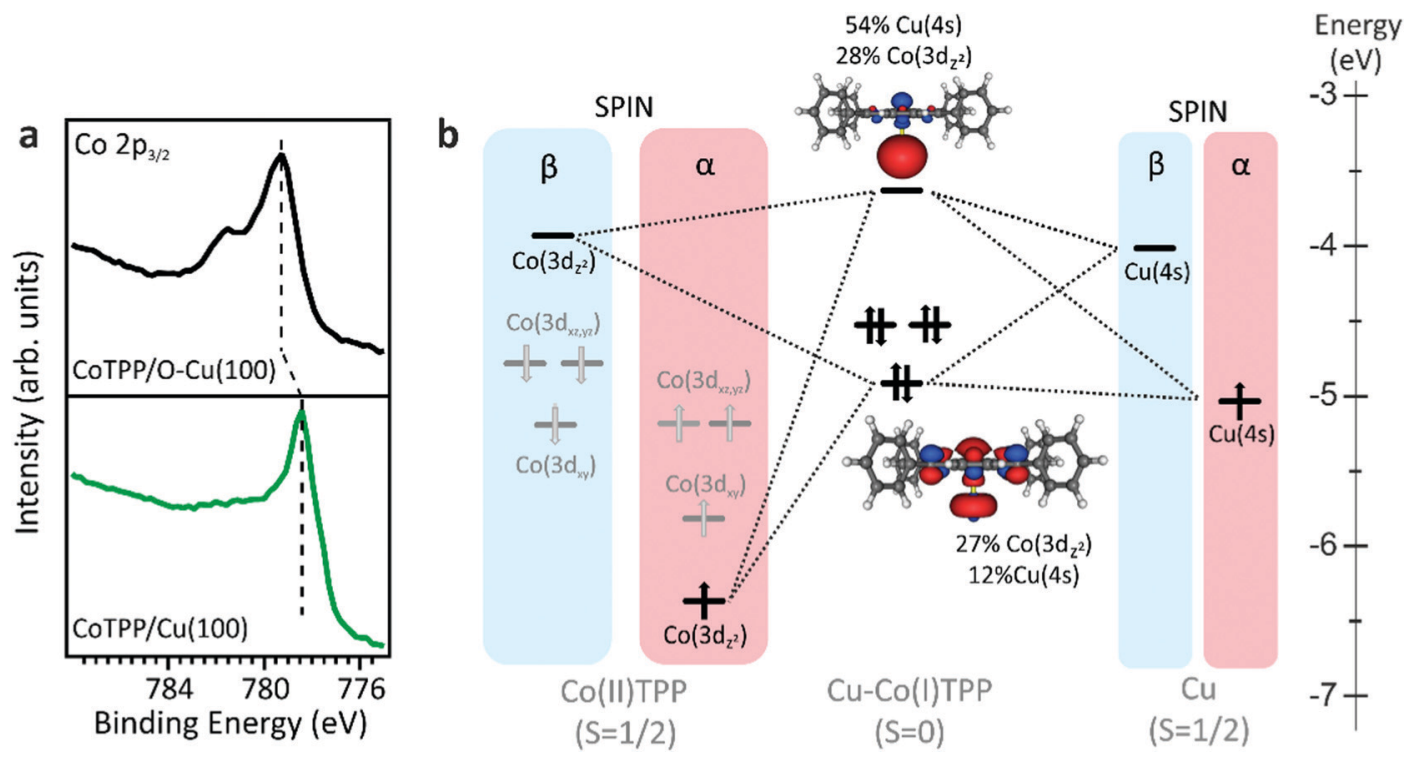

Fig. 1 (a) Co $2 p_{3 / 2}$ XPS core level spectra of CoTPP on bare (bottom panel) and oxygen modified (upper panel) Cu(100). (b) Energy level diagram for selected MOs, Co(3d) and $\mathrm{Cu}(4 \mathrm{~s})$, for LS Cu-CoTPP. 3D plots displayed isosurfaces correspond to $\pm 0.03 \mathrm{e}^{1 / 2} \mathrm{~A}^{-3 / 2}$. Grey and white spheres are representative of $\mathrm{C}$ and $\mathrm{H}$ atoms, respectively. 
spectroscopy (XPS) at the Co 2p core level (see Fig. 1a). The Co $2 \mathrm{p}_{3 / 2}$ spectrum of CoTPP deposited on $\mathrm{O}-\mathrm{Cu}(100)$ shows a shape similar to that of the CoTPP multilayer. ${ }^{4,22}$ More specifically, the intensity maximum is peaked at $779.25 \mathrm{eV}$ in binding energy (BE) and the spectrum displays the characteristic multiplet structure of LS Co(II) with one unpaired electron. On the other hand, the shape and BE (778.4 eV) of the CoTPP/ $\mathrm{Cu}(100) \mathrm{Co} 2 \mathrm{p}_{3 / 2}$ peak are similar to those reported for CoTPP/ $\mathrm{Ag}(111),{ }^{4}$ suggesting the $\mathrm{Co}(\mathrm{II}) \rightarrow \mathrm{Co}(\mathrm{I})$ reduction upon chemisorption of CoTPP on $\mathrm{Cu}(100)$.

Further information about the interaction of CoTPP with the $\mathrm{Cu}(100)$ surface can be gained by means of density functional theory (DFT) calculations. Previous results obtained by exploiting a periodical model ${ }^{21,32,33}$ will be here extended by combining the molecular cluster approach ${ }^{34,35}$ with DFT based calculations, which ultimately allows to gain information about AOs and MOs in the metal-molecule complex. ${ }^{4,36}$ This approach has been used to correctly reproduce the magnetic properties of supported metal porphyrins and phthalocyanines. ${ }^{4,30,37}$

Indeed, the molecular cluster approach has the great advantage of accurately describing the oxidation and spin states of the central ion in metalorganics, ${ }^{38}$ being thus best suited to investigate the Co metal ion chelated in CoTPP, involved herein in the axial coordination. In addition, when combined with first principle calculations, it provides a quantitative analysis on the symmetry restricted covalency (the effect associated with the dilution, ruled by the complex symmetry, of d orbitals making them a linear combinations of AOs-LCAO-MOs ${ }^{39}$ ). Moreover, the molecular cluster approach gives an information about the charge redistribution in the MOs and AOs formed upon interaction and it stands at the basis of XAS simulations, which ultimately give a theoretical feedback on the metal spin state and the metal oxidation state modification.

Our calculation shows that both $\mathrm{Cu}(0)$ and $\mathrm{Co}(\mathrm{II})$ in the $\mathrm{Cu}-$ CoTPP cluster are characterized by the presence of a single unpaired electron occupying the $\mathrm{Cu} 4 \mathrm{~s}$ AO and the Co $3 \mathrm{~d}_{z^{2}}$-based MO (see Fig. 1b), and the molecular complex can be stabilized either in a LS $(S=0)$ or a high spin (HS) state $(S=1)$ configuration. As such, energy deviations $(\Delta E)$ from the Cu-CoTPP ground state (GS) reported in Fig. S2 (see ESI $\dagger$ ) clearly show the LS higher stability for $\mathrm{Cu}-\mathrm{Co}$ distances smaller than 3.6 ̊. A short intermetallic distance appears then to favor the $\mathrm{Co}(\mathrm{II})+\mathrm{Cu}(0) \rightarrow \mathrm{Co}(\mathrm{I})+\mathrm{Cu}(\mathrm{I})$ on-surface redox reaction. Theoretical outcomes reported in Fig. 1 strongly support the presence of a $\mathrm{Cu}(\mathrm{I})-\mathrm{Co}(\mathrm{I}) \mathrm{TPP}$ cluster at a $\mathrm{Co}-\mathrm{Cu}$ distance of $2.5 \AA \AA^{21,32,33}$ in fact, the (CoTPP + Cu) system is less stable than the $\mathrm{Cu}(\mathrm{I})-\mathrm{Co}(\mathrm{I}) \mathrm{TPP}$ cluster by $1.04 \mathrm{eV}$. In particular, the charge transfer that causes the reduction of the cobalt is clearly visible on the MOs CoTPP-Cu compositions in Fig. 1b: the fully occupied MOs is mainly localized on the Co $3 \mathrm{~d}_{z^{2}}$-based MO (27\%), while the LUMO is localized $(54 \%)$ on $\mathrm{Cu} 4 \mathrm{~s}$ MO. This confirms that the direct interaction of the CoTPP molecule with the copper substrate leads to the stabilization of a reduced $\mathrm{Co}(\mathrm{I})$, with no unpaired electrons in the valence states, contrary to the CoTPP/O-Cu(100) system, where the open-shell Co(II) state, characteristic of the free CoTPP molecule, is preserved. The present theoretical output is fully in agreement with the interpretation of the XPS data reported on Fig. 1a.
After stabilizing the Co chelated ion in the two desired configurations, namely, reduced $\mathrm{Co}(\mathrm{I})$ and open-shell $\mathrm{Co}$ (II) on bare and oxygen-modified $\mathrm{Cu}(100)$ substrates, respectively, in the next we elucidate the interplay between spin and oxidation state in the molecular reactivity towards axial ligands. To do so, both the CoTPP arrays have been exposed to a low dose of nitrogen dioxide at RT.

The possible anchoring of the axial ligand to the Co ion in the Co(I)TPP and Co(II)TPP networks formed on the bare and oxygen-modified surfaces, respectively, was monitored by means of XPS. Both the Co $2 \mathrm{p}_{3 / 2}$ and $\mathrm{N}$ 1s core-level spectra of $\mathrm{Co}(\mathrm{II}) \mathrm{TPP}$ deposited on the $\mathrm{O}-\mathrm{Cu}(100)$ substrate remained unchanged after the exposure at RT to the $\mathrm{NO}_{2}$ gas (see Fig. S3, $\mathrm{ESI} \dagger)$. This result indicates that the sole presence of an unpaired electron in the $\mathrm{Co}$ (II) ion may not be the key requirement for anchoring gas molecules to the metal-organic network, as previously discussed in the literature, ${ }^{4,6}$ or, at least, it is not sufficient.

In contrast with the CoTPP/O- $\mathrm{Cu}(100)$ system, the Co $2 \mathrm{p}_{3 / 2}$ and $\mathrm{N}$ 1s spectra of CoTPP deposited on the bare $\mathrm{Cu}(100)$ substrate show well-evident changes after the exposure of the metalloporphyrin network to $\mathrm{NO}_{2}$. The $\mathrm{N}$ 1s spectrum exhibits a new peak at $402.8 \mathrm{eV}$ associated with $\mathrm{NO}_{2}$ and a small energy shift to lower BE of the main peak associated with the tetrapyrrolic nitrogen atoms (see Fig. 2). For what concerns the Co $2 \mathrm{p}_{3 / 2}$ spectrum, the intensity maximum is shifted by $1.95 \mathrm{eV}$ to higher BE and a different distribution of satellites is observed after exposing the system to $\mathrm{NO}_{2}$. This spectral behavior is consistent with the $\mathrm{Co}(\mathrm{I})$ oxidation induced by the interaction with the axial ligand and the formation of a $\mathrm{Co}-\mathrm{NO}_{2}$ bond. However, the Co $2 \mathrm{p}_{3 / 2}$ core level and the Co L-edge near-edge $\mathrm{X}$-ray absorption fine structure (NEXAFS) spectra of the Co- $\mathrm{NO}_{2}$ system are different from the one of CoTPP/O-Cu(100) where the LS Co(II) is present (see Fig. S4, ESI $\dagger$ ). Hence, the stabilization of the $\mathrm{Cu}(100) / \mathrm{CoTPP}-\mathrm{NO}_{2}$ complex probably leads to the Co(III) oxidation state.

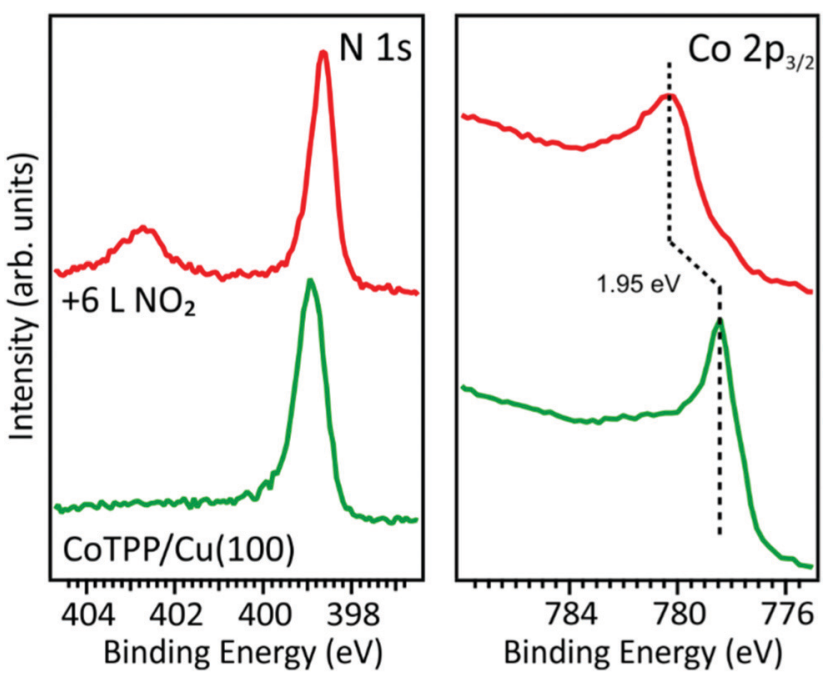

Fig. $2 \mathrm{~N}$ 1s and Co $2 \mathrm{p}_{3 / 2}$ XPS core level spectra of CoTPP deposited on the bare copper substrate, before and after $6 \mathrm{~L} \mathrm{NO}_{2}$ dose. 
To support these experimental observations and to provide a detailed insight into the stabilization of Co(III) ions in the metal porphyrin array, further DFT-based numerical simulations and additional NEXAFS simulations have been performed.

The $\mathrm{NO}_{2}$ interaction with the $\mathrm{Co}(\mathrm{I}) \mathrm{TPP}$ array has been modeled by exploiting the $\mathrm{Cu}-\mathrm{CoTPP}-\mathrm{NO}_{2}$ cluster, whose constrained optimization has been carried out by assuming either 3 or 1 unpaired electrons and freezing the $\mathrm{Cu}-\mathrm{Co}$ distance to $3 \AA$ A i.e., a value close to the one $(2.93 \AA)^{21}$ optimized for the $\mathrm{Cu}-\mathrm{Co}$ bond by means of DFT periodic calculations for similar interfaces. As such, it can be useful to anticipate that bondlength variations smaller than $0.1 \AA$ do not significantly affect the modeled NEXAFS spectra reported herein. Thus, since the LS Cu-CoTPP- $\mathrm{NO}_{2}$ cluster is more stable than the HS one by $1.06 \mathrm{eV}$, only the former has been considered in the forthcoming discussion.

Upon the $\mathrm{Co}-\mathrm{NO}_{2}$ bond formation, the energy of the $\mathrm{Cu}-\mathrm{Co}$ bond decreases from $1.06 \mathrm{eV}$ (Cu-CoTPP) to $0.33 \mathrm{eV}$ (Cu-CoTPP$\mathrm{NO}_{2}$ ) (see Fig. S5, ESI $\dagger$ ) and the same holds when CoTPP-NO $\mathrm{N}_{2}$ (see Fig. S7 in the ESI $\dagger$ ) and the $\mathrm{Cu}-\mathrm{COTPP}-\mathrm{NO}_{2}$ are compared, in particular, the $\mathrm{Co}-\mathrm{NO}_{2}$ bonding interaction decreases from $1.31 \mathrm{eV}$ to $0.77 \mathrm{eV}$. Beside the recognition of the orbitals mainly contributing to the $\mathrm{Cu}-\mathrm{CoTPP}-\mathrm{NO}_{2}$ interaction $\left(\mathrm{Cu} 4 \mathrm{~s}\right.$ and $\mathrm{Co} 3 \mathrm{~d}_{z^{2}}$ AOs and the $\mathrm{NO}_{2} \pi^{*} \mathrm{MO}$ ), the analysis of the $\mathrm{Cu}-\mathrm{CoTPP}-\mathrm{NO}_{2}$ electronic structure reveals that the singly occupied MO (SOMO) is strongly localized on the $\mathrm{Cu} 4 \mathrm{~s} \mathrm{AO}$. This suggests that the trans-effect induced by the $\mathrm{NO}_{2}$ coordination implies the weakening of the $\mathrm{Cu}-\mathrm{Co}$ interaction and the reduction of the $\mathrm{Cu}$ oxidation number to its original value (0). It has to be noted that upon adsorption of CoTPP on the bare copper, the strong interaction between Co(II) and the surface, beside inducing the $\mathrm{Co}(\mathrm{II}) \rightarrow \mathrm{Co}(\mathrm{I})$ reduction, could also introduce a mechanical strain within the molecule. After the $\mathrm{NO}_{2}$ trans-coordination to the supported CoTPP, being $\mathrm{NO}_{2}$ a stronger ligand than the copper surface, the $\mathrm{Co}-\mathrm{Cu}$ distance increases of $0.5 \AA$, thus reducing possible molecular strains. Moreover, the doubly occupied $\mathrm{MO}$ accounting for the $\mathrm{Co}-\mathrm{NO}_{2}$ bonding is mainly localized on $\mathrm{NO}_{2}$ with a negligible $\mathrm{Cu}$ participation (see Fig. 3, right panel), while the Co $3 \mathrm{~d}_{z^{2}}$ AO mainly contributes to the lowest unoccupied MO. As a whole, the $\mathrm{NO}_{2}$ local electronic structure of the $\mathrm{Cu}$-CoTPP- $\mathrm{NO}_{2}$ cluster corresponds to a closed-shell with $\mathrm{Cu}$ in its elemental oxidation state and the "octahedrally" coordinated Co ion having a formal +3 oxidation state and a $\mathrm{LS} 3 \mathrm{~d}^{6}$ electronic configuration with the $3 d_{x^{2}-y^{2}}$ and $3 d_{z^{2}}$ as empty orbitals.

As such, it has to be noted that Co(III), here observed in the surface supported 2D metal-organic array, has been formerly described only for metal-organic complexes in solution. ${ }^{40}$ To single out perturbations induced by the surface on the CoTPP- $\mathrm{NO}_{2} \mathrm{MOs}$, an analysis of the CoTPP- $\mathrm{NO}_{2}$ and $\mathrm{Cu}-\mathrm{CoTPP}-\mathrm{NO}_{2}$ frontier orbitals has been performed (Section S6, ESI $\dagger$ ). Theoretical results indicate that, even though Co 3d-based and $\mathrm{NO}_{2}$-based MOs (see Fig. S7, $\mathrm{ESI} \dagger$ ) are quite similar in the two clusters, both their energies and localizations are different, hence a $\mathrm{Cu}-\mathrm{Co}$ weak interaction is still present in the $\mathrm{Cu}-\mathrm{CoTPP}-\mathrm{NO}_{2}$ cluster. The calculated binding energies and geometrical structures are further supported by the analysis of the Nalewajski-Mrozek bond multiplicity indexes $\left({ }^{\mathrm{NM}} \mathrm{I}\right),{ }^{41}$ which provide a quantitative estimate of bond strengths.
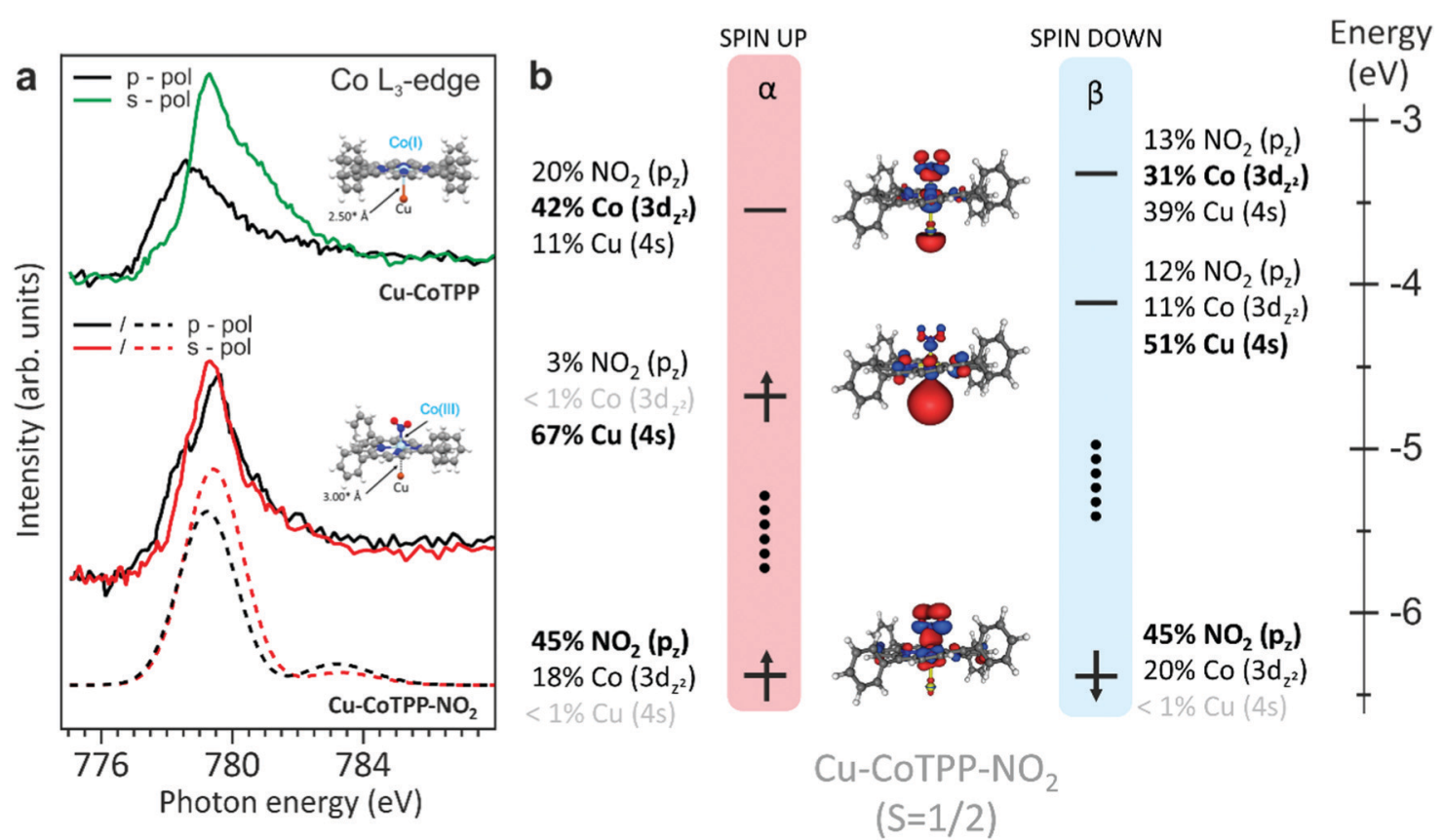

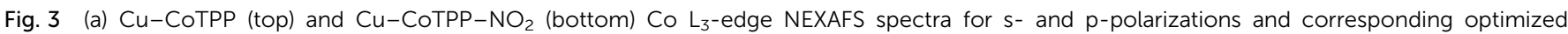

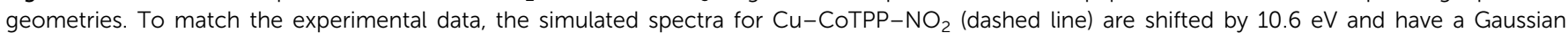

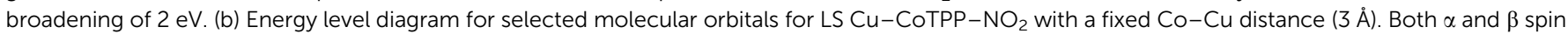

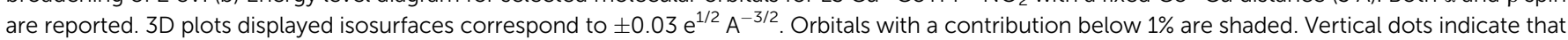

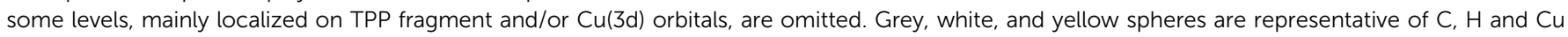
atoms, respectively. 
In both $\mathrm{Cu}-\mathrm{CoTPP}$ and CoTPP- $\mathrm{NO}_{2}$ clusters, the Co species $(\mathrm{Co}(\mathrm{I})$ in the former, $\mathrm{Co}$ (III) in the latter) is penta-coordinated and the quite large ${ }^{\mathrm{NM}} \mathrm{I}_{\mathrm{Co}-\mathrm{Cu}}$ and ${ }^{\mathrm{NM}} \mathrm{I}_{\mathrm{Co}-\mathrm{NO}_{2}}$ values (0.95 and 0.69, respectively) are indicative of a quite strong $\mathrm{Co}-\mathrm{Cu}$ and $\mathrm{Co}-\mathrm{N}_{\mathrm{NO}_{2}}$ bond. Interestingly, ${ }^{\mathrm{NM}} \mathrm{I}_{\mathrm{Co}-\mathrm{Cu}}$ values are 0.95 to 0.16 in $\mathrm{Cu}-\mathrm{CoTPP}$ and $\mathrm{Cu}-\mathrm{CoTPP}-\mathrm{NO}_{2}$, respectively, suggesting that the coordination of the sixth ligand $\left(\mathrm{NO}_{2}\right)$ dramatically weakens the $\mathrm{Cu}-\mathrm{Co}$ bonding. At the same time, calculations indicate a not significant decreasing of the ${ }^{\mathrm{NM}} \mathrm{I}_{\mathrm{Co}-\mathrm{NO}_{2}}$ going from the CoTPP- $\mathrm{NO}_{2}$ (0.69) to the Cu-CoTPP$\mathrm{NO}_{2}$ (0.61) complex. As a whole, Co is esa-coordinated in the $\mathrm{Cu}-\mathrm{CoTPP}-\mathrm{NO}_{2}$ cluster, but the $\mathrm{Co}-\mathrm{Cu}$ interaction is significantly weakened by the $\mathrm{NO}_{2}$ presence, while negligible bond order variations affect the Co-ligand interactions taking place in the macrocycle (see Table S8 in the ESI $\dagger$ ).

Further information about the Co(III) stabilization at the metal-organic interface has been gained by recording, modelling and assigning the Co $\mathrm{L}_{3}$-edge absorption spectra (see Fig. 3a) after exposure of the CoTPP/Cu(100) interface to $6 \mathrm{~L}$ of $\mathrm{NO}_{2}$. Clear differences can be observed in the spectra reported in Fig. 3 with respect to the ones measured for CoTPP/ $\mathrm{O}-\mathrm{Cu}(100)$ reported in Fig. S4 (ESI $\dagger$ ).

Co $\mathrm{L}_{3}$-edge spectra for $\mathrm{s}$ - and p-polarizations have been modelled by exploiting the optimized $\mathrm{Cu}-\mathrm{CoTPP}-\mathrm{NO}_{2}$ cluster (see Fig. S5, ESI $\dagger$ ) for which a LS state (1 unpaired electron) has been assumed. As already mentioned, $3 \mathrm{~d}_{x z}, 3 \mathrm{~d}_{y z}$ and $3 \mathrm{~d}_{x y}$ orbitals for the $3 d^{6} \mathrm{Co}$ (III) species are fully occupied, while the others MOs are empty and the $\mathrm{Cu}-\mathrm{CoTPP}-\mathrm{NO}_{2} \mathrm{SOMO}$, as stated above, is strongly localized on the $\mathrm{Cu} 4 \mathrm{~s} \mathrm{AO}$. The lower excitation energy (EE) side of the single peak characterizing the modelled Co $\mathrm{L}_{3}$-edge spectrum in p-polarization includes both $\Delta S=0,+1$ electronic states. $\Delta S=0$ states are generated by single electronic excitations from the Co 2p orbitals to the Co-based $\mathrm{d}_{z^{2}}$ and $\mathrm{d}_{x^{2}-y^{2}}$ virtual MOs (VMOs), while both Co-based and TPP-based VMOs are involved in electronic excitations generating $\Delta S=+1$ states. At variance to that, the higher EE side of the peak only includes $\Delta S=0$ electronic states, which are determined by electronic transitions from the Co 2p AOs to the $\mathrm{Cu}$ $4 \mathrm{~s}$-based SOMO and Co-based VMOs. Only $\Delta S=0$ states, mainly generated by Co $2 \mathrm{p} \rightarrow$ Co-based $\mathrm{d}_{x^{2}-y^{2}}$ single electronic excitations, contribute to the s-polarized spectrum. The overall agreement between experimental and modelled spectra, in particular the energy position of the main peaks and the linear dichroic behaviour observed in the spectra, fully supports the stabilization of the Co(III) species upon the interaction of the $\mathrm{NO}_{2}$ ligand with the Co(I)TPP species stabilized on the $\mathrm{Cu}(100)$ substrate.

The reversibility of the molecular-surface interaction and, accordingly, the $\mathrm{Co}(\mathrm{I}) \leftrightarrows \mathrm{Co}(\mathrm{III})$ redox reaction has been tested here by annealing the $\mathrm{NO}_{2}-\mathrm{CoTPP} / \mathrm{Cu}(100)$ interface to $450 \mathrm{~K}$ under UHV conditions. The possible thermal desorption of $\mathrm{NO}_{2}$ and restoring of the $\mathrm{Co}-\mathrm{Cu}$ interaction has been monitored by valence band spectroscopy (see Fig. 4). This, being an experimental technique sensitive to the changes in charge transfer and interaction strength at the metal-organic/metal interface, allows to confirm the presence of the surface trans-effect, as suggested by calculations.
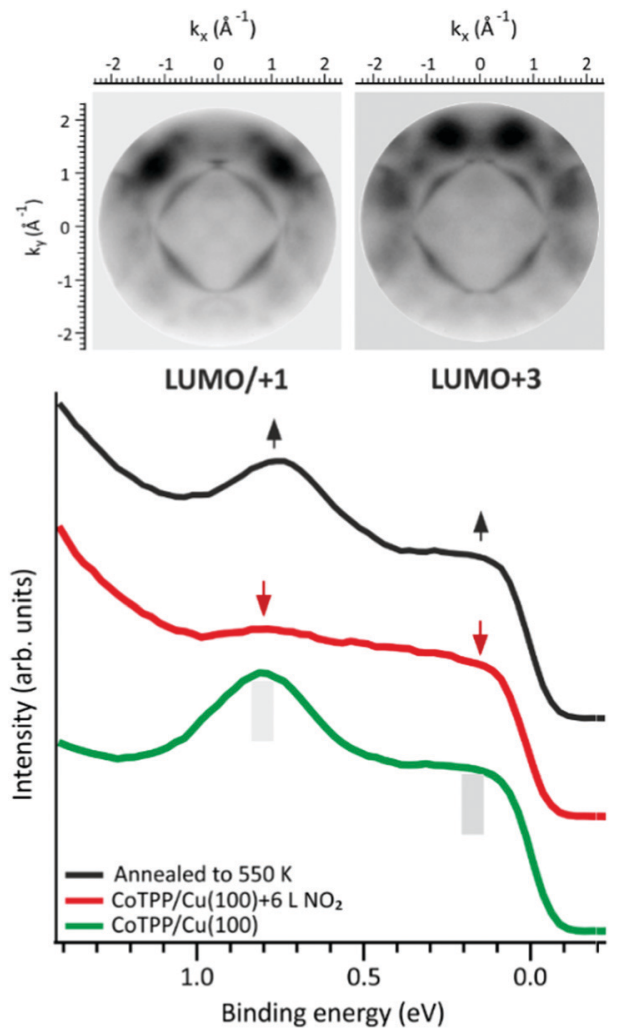

Fig. 4 Bottom panel: Photoemission spectra of CoTPP/Cu(100), after $\mathrm{NO}_{2}$ dosing and after annealing of $\mathrm{NO}_{2}-\mathrm{CoTPP} / \mathrm{Cu}(100)$ to $450 \mathrm{~K}$; top panel: experimental 2D momentum patterns of CoTPP/Cu(100) corresponding to LUMO/LUMO+1 and LUMO+3 MOs. The sharp inner features are related to the sp band of the copper surface.

The valence band spectrum of the clean copper is dominated by the sp band and has a rather featureless plateau, while the CoTPP/Cu(100) spectrum shows two prominent features at BEs of $0.15 \mathrm{eV}$ and $0.80 \mathrm{eV}$. To clarify the origin of these features we measured momentum resolved photoemission maps at constant $\mathrm{BE}$ and compared them with the square modulus of the Fourier transform (FT) of the real space MOs provided by DFT calculation, $^{42}$ within the photoemission tomography (PT) approach (see Fig. S9, ESI $\dagger$ ). Based on the excellent match between the experimental and theoretical data, the features at $0.15 \mathrm{eV}$ and $0.80 \mathrm{eV} \mathrm{BE}$ can be assigned to the emissions from the gas-phase LUMO/LUMO+1 and the LUMO+3, respectively. These molecular levels, delocalized over the entire molecular macrocycle of CoTPP, are filled due to the charge transfer occurring at the organic/metal interface, as a result of the strong anchoring of the Co ion to the copper substrate. ${ }^{43,44}$ As discussed above, in the $\mathrm{Cu}-$ CoTPP- $\mathrm{NO}_{2}$ complex the $\mathrm{Co}-\mathrm{Cu}$ interaction is weakened by the surface trans-effect, as evident from the quenching of the LUMOs features (see Fig. 4). The annealing of the interface to $450 \mathrm{~K}$ induces the thermal desorption of the $\mathrm{NO}_{2}$ ligand in the $\mathrm{Cu}-$ CoTPP- $\mathrm{NO}_{2}$ complex, thus restoring the pristine interaction and the charge transfer between the copper surface and the CoTPP molecule. As a result, both LUMO states reappear in the valence band spectra. The Co $2 \mathrm{p}_{3 / 2}$ and $\mathrm{N}$ 1s spectra further confirm the 
full reversibility of the $\mathrm{Co}(\mathrm{I}) \leftrightarrows \mathrm{Co}(\mathrm{III})$ conversion (see Fig. S10, $\mathrm{ESI} \dagger)$.

\section{Conclusions}

Using XPS and NEXAFS data supported by DFT calculation highly sensitive to the atomic and molecular characters of metalorganic complexes, we have studied the axial ligand coordination with the cobalt tetraphenylporphyrin array deposited on bare and oxygen passivated copper surfaces. The data show that the Co- $\mathrm{NO}_{2}$ chemical interaction is taking place on the CoTPP network supported by the copper electrode, where the Co ion is in a low and unusual oxidation state (I). Instead, this reaction has not been observed at the CoTPP/O-Cu(100) interface where Co(II) ions have a LS state and a single unpaired electron in the valence shell. The trans-effect observed along the $\mathrm{Cu}-\mathrm{Co}-\mathrm{N}$ axis in the $\mathrm{Cu}-\mathrm{CoTPP}-\mathrm{NO}_{2}$ complex suppresses the $\mathrm{Cu}-\mathrm{Co}$ interaction, as confirmed by the valence band data, and stabilizes the $\mathrm{Co}(\mathrm{III})$ chelated ion in the metal-organic array. The $\mathrm{Co}(\mathrm{I}) \leftrightarrows \mathrm{Co}(\mathrm{III})$ conversion is fully reversible, as the thermal-induced desorption of $\mathrm{NO}_{2}$ taking place at $450 \mathrm{~K}$ restores the pristine $\mathrm{Co}-\mathrm{Cu}$ interaction.

Our experiment demonstrates that the on-surface reactivity towards axial coordination to the metal center of porphyrin 2D arrays is driven by the oxidation state, rather than by the presence of an unpaired electron in the $\mathrm{d}_{z^{2}}$ atomic orbital. Further, the reduction of the chelated metal by surface transeffect may be reversed by the axial coordination to $\mathrm{NO}_{2}$ through a push-pull charge transfer mechanism. This evidence lets us envisage the possibility of tuning the metal spin state of $2 \mathrm{D}$ arrays of metal-organic molecules by suitable choice of the substrate and reacting gas.

We remark that the combination of surface trans-effect and axial coordination to $\mathrm{NO}_{2}$ allowed us to manipulate the Co oxidation and spin states at room temperature. This is a key aspect for the generalization of our approach to ferromagnetic substrates, as well as for the practical use in molecular-based spintronic devices.

\section{Author contributions}

I. C. and V. F. performed the experiments and drafted the manuscript with essential contributions from S. C., M. C. and L. F.; all the authors strongly participated in the discussion of the results and revision of the manuscript. S. C. and M. C. performed the computational calculations. L. S. and L. F. gave significant assistance in the XPS and NEXAFS experiments.

\section{Conflicts of interest}

There are no conflicts to declare.

\section{Notes and references}

1 J. M. Gottfried, Surf. Sci. Rep., 2015, 70, 259-379.
2 B. Hulsken, R. Van Hameren, J. W. Gerritsen, T. Khoury, P. Thordarson, M. J. Crossley, A. E. Rowan, R. J. M. Nolte, J. A. A. W. Elemans and S. Speller, Nat. Nanotechnol., 2007, 2, 285-289.

3 K. S. Mali, N. Pearce, S. De Feyter and N. R. Champness, Chem. Soc. Rev., 2017, 46, 2520-2542.

4 W. Hieringer, K. Flechtner, A. Kretschmann, K. Seufert, W. Auwärter, J. V. Barth, A. Görling, H. P. Steinrück and J. M. Gottfried, J. Am. Chem. Soc., 2011, 133, 6206-6222.

5 C. Wäckerlin, K. Tarafder, J. Girovsky, J. Nowakowski, T. Hählen, A. Shchyrba, D. Siewert, A. Kleibert, F. Nolting, P. M. Oppeneer, T. A. Jung and N. Ballav, Angew. Chem., Int. Ed., 2013, 52, 4568-4571.

6 C. Wäckerlin, D. Chylarecka, A. Kleibert, K. Müller, C. Iacovita, F. Nolting, T. A. Jung and N. Ballav, Nat. Commun., 2010, 1, 61.

7 H. Kim, Y. H. Chang, S. H. Lee, Y. H. Kim and S. J. Kahng, ACS Nano, 2013, 7, 9312-9317.

8 M. Viviani, L. Girlanda, A. Kievsky and L. E. Marcucci, Phys. Rev. C, 2020, 102, 245406.

9 M. H. Chang, N. Y. Kim, Y. H. Chang, Y. Lee, U. S. Jeon, H. Kim, Y. H. Kim and S. J. Kahng, Nanoscale, 2019, 11, 8510-8517.

10 D. E. Hurtado Salinas, A. Sarasola, B. Stel, F. P. Cometto, K. Kern, A. Arnau and M. Lingenfelder, ACS Omega, 2019, 4, 9850-9859.

11 G. Zamborlini, M. Jugovac, A. Cossaro, A. Verdini, L. Floreano, D. Lüftner, P. Puschnig, V. Feyer and C. M. Schneider, Chem. Commun., 2018, 54, 13423-13426.

12 C. Wäckerlin, D. Siewert, T. A. Jung and N. Ballav, Phys. Chem. Chem. Phys., 2013, 15, 16510-16514.

13 L. Xue, G. Farrugia, S. M. Miller, C. D. Ferris, S. H. Snyder and J. H. Szurszewski, Proc. Natl. Acad. Sci. U. S. A., 2000, 97, 1851-1855.

14 J. P. Collman, R. Boulatov, C. J. Sunderland and L. Fu, Chem. Rev., 2004, 104, 561-588.

15 J. M. C. Ribeiro, J. M. H. Hazzard, R. H. Nussenzveig, D. E. Champagne and F. A. Walker, Science, 1993, 260, 539-541.

16 R. Gutzler, S. Stepanow, D. Grumelli, M. Lingenfelder and K. Kern, Acc. Chem. Res., 2015, 48, 2132-2139.

17 C. Wäckerlin, K. Tarafder, D. Siewert, J. Girovsky, T. Hählen, C. Iacovita, A. Kleibert, F. Nolting, T. A. Jung, P. M. Oppeneer and N. Ballav, Chem. Sci., 2012, 3, 3154-3160.

18 S. Scheller, M. Goenrich, R. Boecher, R. K. Thauer and B. Jaun, Nature, 2010, 465, 606-608.

19 S. J. Moore, S. T. Sowa, C. Schuchardt, E. Deery, A. D. Lawrence, J. V. Ramos, S. Billig, C. Birkemeyer, P. T. Chivers, M. J. Howard, S. E. J. Rigby, G. Layer and M. J. Warren, Nature, 2017, 543, 78-82.

20 T. Wagner, J. Kahnt, U. Ermler and S. Shima, Angew. Chem., Int. Ed., 2016, 55, 10630-10633.

21 Y. H. Chang, H. Kim, S. J. Kahng and Y. H. Kim, Dalton Trans., 2016, 45, 16673-16681.

22 S. Vijayaraghavan, W. Auwärter, D. Ecija, K. Seufert, S. Rusponi, T. Houwaart, P. Sautet, M. L. Bocquet, 
P. Thakur, S. Stepanow, U. Schlickum, M. Etzkorn, H. Brune and J. V. Barth, ACS Nano, 2015, 9, 3605-3616.

23 L. M. Arruda, M. E. Ali, M. Bernien, N. Hatter, F. Nickel, L. Kipgen, C. F. Hermanns, T. Bißwanger, P. Loche, B. W. Heinrich, K. J. Franke, P. M. Oppeneer and W. Kuch, Phys. Chem. Chem. Phys., 2020, 22, 12688-12696.

24 P. S. Deimel, R. M. Bababrik, B. Wang, P. J. Blowey, L. A. Rochford, P. K. Thakur, T. L. Lee, M. L. Bocquet, J. V. Barth, D. P. Woodruff, D. A. Duncan and F. Allegretti, Chem. Sci., 2016, 7, 5647-5656.

25 T. Lukasczyk, K. Flechtner, L. R. Merte, N. Jux, F. Maier, J. M. Gottfried and H. P. Steinrück, J. Phys. Chem. C, 2007, 111, 3090-3098.

26 S. S. Eaton and G. R. Eaton, Inorg. Chem., 1980, 19, 1095-1096.

27 G. Fratesi, S. Achilli, A. Ugolotti, A. Lodesani, A. Picone, A. Brambilla, L. Floreano, A. Calloni and G. Bussetti, Appl. Surf. Sci., 2020, 530, 147085.

28 A. Calloni, M. S. Jagadeesh, G. Bussetti, G. Fratesi, S. Achilli, A. Picone, A. Lodesani, A. Brambilla, C. Goletti, F. Ciccacci, L. Duò, M. Finazzi, A. Goldoni, A. Verdini and L. Floreano, Appl. Surf. Sci., 2020, 505, 144213.

29 I. Cojocariu, H. M. Sturmeit, G. Zamborlini, A. Cossaro, A. Verdini, L. Floreano, E. D'Incecco, M. Stredansky, E. Vesselli, M. Jugovac, M. Cinchetti, V. Feyer and C. M. Schneider, Appl. Surf. Sci., 2020, 504, 144343.

30 X. Yang, I. Krieger, D. Lüftner, S. Weiß, T. Heepenstrick, M. Hollerer, P. Hurdax, G. Koller, M. Sokolowski, P. Puschnig, M. G. Ramsey, F. S. Tautz and S. Soubatch, Chem. Commun., 2018, 54, 9039-9042.

31 I. Cojocariu, S. Carlotto, H. M. Sturmeit, G. Zamborlini, M. Cinchetti, A. Cossaro, A. Verdini, L. Floreano, M. Jugovac, P. Puschnig, C. Piamonteze, M. Casarin, V. Feyer and C. M. Schneider, Chem. - Eur. J., 2021, 27, 3526-3535.

32 P. Donovan, A. Robin, M. S. Dyer, M. Persson and R. Raval, Chem. - Eur. J., 2010, 16, 11641-11652.
33 B. W. Heinrich, C. Iacovita, T. Brumme, D. J. Choi, L. Limot, M. V. Rastei, W. A. Hofer, J. Kortus and J. P. Bucher, J. Phys. Chem. Lett., 2010, 1, 1517-1523.

34 M. Casarin, F. Ferrigato, C. Maccato and A. Vittadini, J. Phys. Chem. B, 2005, 109, 12596-12602.

35 M. Casarin, C. Maccato and A. Vittadini, J. Phys. Chem. B, 2002, 106, 795-802.

36 S. Carlotto, M. Casarin, A. Lanza, F. Nestola, L. Pandolfo, C. Pettinari and R. Scatena, Cryst. Growth Des., 2015, 15, 5910-5918.

37 S. Carlotto, M. Sambi, F. Sedona, A. Vittadini, J. Bartolomé, F. Bartolomé and M. Casarin, Phys. Chem. Chem. Phys., 2016, 18, 28110-28116.

38 T. Houwaart, T. Le Bahers, P. Sautet, W. Auwärter, K. Seufert, J. V. Barth and M.-L. Bocquet, Surf. Sci., 2015, 635, 108-114.

39 H. L. Schläfer, Absorption Spectra and Chemical Bonding in Complexes, 2021, https:/www.elsevier.com/books/ absorption-spectra-and-chemical-bonding-in-complexes/jor gensen/978-0-08-009627-8.

40 P. Kumar, Y. M. Lee, Y. J. Park, M. A. Siegler, K. D. Karlin and W. Nam, J. Am. Chem. Soc., 2015, 137, 4284-4287.

41 R. F. Nalewajski and J. Ozek, Int. J. Quantum Chem., 1994, 51, 187-200.

42 P. Puschnig, S. Berkebile, A. J. Fleming, G. Koller, K. Emtsev, T. Seyller, J. D. Riley, C. Ambrosch-Draxl, F. P. Netzer and M. G. Ramsey, Science, 2009, 326, 702-706.

43 G. Zamborlini, D. Lüftner, Z. Feng, B. Kollmann, P. Puschnig, C. Dri, M. Panighel, G. Di Santo, A. Goldoni, G. Comelli, M. Jugovac, V. Feyer and C. M. Schneider, Nat. Commun., 2017, 8, 1-8.

44 H. M. Sturmeit, I. Cojocariu, M. Jugovac, A. Cossaro, A. Verdini, L. Floreano, A. Sala, G. Comelli, S. Moro, M. Stredansky, M. Corva, E. Vesselli, P. Puschnig, C. M. Schneider, V. Feyer, G. Zamborlini and M. Cinchetti, J. Mater. Chem. C, 2020, 8, 8876-8886. 